\title{
Improving patient-practitioner interaction in chronic pain rehabilitation
}

Citation for published version (APA):

Stinesen, B. B., Sneijder, P., Koke, A. J. A., \& Smeets, R. J. E. M. (2019). Improving patient-practitioner interaction in chronic pain rehabilitation. Scandinavian Journal of Pain, 19(4), 843-853.

https://doi.org/10.1515/sjpain-2019-0034

Document status and date:

Published: 01/10/2019

DOI:

10.1515/sjpain-2019-0034

Document Version:

Publisher's PDF, also known as Version of record

Document license:

Taverne

Please check the document version of this publication:

- A submitted manuscript is the version of the article upon submission and before peer-review. There can be important differences between the submitted version and the official published version of record.

People interested in the research are advised to contact the author for the final version of the publication, or visit the DOI to the publisher's website.

- The final author version and the galley proof are versions of the publication after peer review.

- The final published version features the final layout of the paper including the volume, issue and page numbers.

Link to publication

\footnotetext{
General rights rights.

- You may freely distribute the URL identifying the publication in the public portal. please follow below link for the End User Agreement:

www.umlib.nl/taverne-license

Take down policy

If you believe that this document breaches copyright please contact us at:

repository@maastrichtuniversity.nl

providing details and we will investigate your claim.
}

Copyright and moral rights for the publications made accessible in the public portal are retained by the authors and/or other copyright owners and it is a condition of accessing publications that users recognise and abide by the legal requirements associated with these

- Users may download and print one copy of any publication from the public portal for the purpose of private study or research.

- You may not further distribute the material or use it for any profit-making activity or commercial gain

If the publication is distributed under the terms of Article $25 \mathrm{fa}$ of the Dutch Copyright Act, indicated by the "Taverne" license above, 


\title{
Short communication
}

\section{Baukje B. Stinesen*, Petra Sneijder, Albère J.A. Köke and Rob J.E.M. Smeets \\ Improving patient-practitioner interaction in chronic pain rehabilitation}

\author{
The merits of a discursive psychological approach
}

https://doi.org/10.1515/sjpain-2019-0034

Received February 20, 2019; revised April 1, 2019; accepted April 15, 2019

\begin{abstract}
Stimulating patients to approach their pain from a biopsychosocial perspective is central to chronic pain rehabilitation. However, conversations between patients and their healthcare professionals about the social and psychological factors that may contribute to the continuation of pain and disability can be challenging. The current scientific literature does not sufficiently pinpoint the difficulties in patient-practitioner interaction on chronic pain, and it falls short of answering the question of how a joint exploration of the social and psychological factors that might be involved in the patient's pain and evolving disability can be enhanced. In this theoretical article, we introduce discursive psychology as a potentially valuable research perspective to gain a better understanding of the difficulties in patient-practitioner interaction in the context of chronic pain rehabilitation. Discursive psychology focuses on features of people's talk (e.g. that of patients and practitioners) and is concerned with the social
\end{abstract}

\footnotetext{
*Corresponding author: Baukje B. Stinesen, Research Group Cross-Media Communication in the Public Domain, HU University of Applied Sciences Utrecht, Utrecht, The Netherlands; and Department of Rehabilitation Medicine, Research School CAPHRI, Maastricht University, Maastricht, The Netherlands,

E-mail: baukje.stinesen@hu.nl

Petra Sneijder: Research Group Cross-Media Communication in the Public Domain, HU University of Applied Sciences Utrecht, Utrecht, The Netherlands

Albère J.A. Köke: Department of Rehabilitation Medicine, Research School CAPHRI, Maastricht University, Maastricht, The Netherlands; Adelante Centre of Expertise in Rehabilitation and Audiology, Hoensbroek, The Netherlands; and Zuyd University of Applied Sciences, Faculty of Health and Technology, Heerlen, The Netherlands

Rob J.E.M. Smeets: Department of Rehabilitation Medicine, Research School CAPHRI, Maastricht University, Maastricht, The Netherlands; and CIR Revalidatie, Eindhoven/Zwolle, The Netherlands
}

practices that people perform as part of a specific interactional context. In this paper, we provide an introduction to the main theoretical notions of discursive psychology. We illustrate how discursive psychological analyses can inform our understanding of the specific sensitivities in conversations between patients with chronic pain and their practitioners. Finally, we address how a better understanding of these sensitivities offers a gateway towards improving these conversations.

Keywords: chronic pain; patient-practitioner interaction; discursive psychology.

\section{Introduction}

\subsection{Chronic pain and rehabilitation}

Social factors and psychological factors play an important role in the development of chronic pain [1-3]. They may contribute to the continuation of the pain and the evolving limitations that patients experience in their daily lives [1, 2]. As no medical cure exists for chronic pain, interdisciplinary chronic pain rehabilitation programmes are aimed at stimulating and enabling patients to think about and deal with their pain differently, and to increase their functioning and quality of life [4-6]. Various healthcare professionals (i.e. a rehabilitation physician, physiotherapist, occupational therapist, psychologist, and social worker) work together in a team around the patient. They aim to help patients to reconceptualise their pain, shifting from a traditional understanding of pain as a measure of tissue injury, towards a biopsychosocial understanding of their pain $[4,7,8]$. To achieve optimal treatment outcomes, it is important that patients and their practitioners develop a shared understanding of the causal and maintaining factors that have contributed and still contribute to their pain and perceived disability $[6,9,10]$. 


\subsection{Impediments to a shared understanding of a patient's pain}

In practice however, a shared understanding of a patient's pain is often difficult to achieve, as talking to patients about the social and psychological aspects of their pain can be challenging. A study by May et al. has reported that patients who were interviewed prior to their first appointment at a rehabilitation unit expressed their frustration with healthcare professionals' inability to come up with a physical explanation for their pain and resisted the suggestion that psychological factors could contribute to their health situation [11]. A strong focus by a patient on the physical aspects of his/her pain is problematic, because it may hinder a comprehensive exploration of the causal and maintaining factors of that pain and disability, including social and psychological ones. Therefore, it can be a barrier in the patient's process of becoming aware of how he/she can take part in solving his/her disabilities. Therefore, when practitioners experience a strong focus on biomedical explanations and resistance to exploring potential social and psychological explanations during their first encounters with the patient, they may deem the patient unsuited to take part in a rehabilitation programme [12], and the patient runs the risk of being excluded from treatment at an early stage. Improving the communication between patients and their healthcare professionals in a way that facilitates an open conversation about the social and psychological aspects of pain thus seems to be a prerequisite for success in chronic pain rehabilitation.

\subsection{It remains unclear how patient-practitioner interaction can be enhanced}

The literature confirms that the way patients and practitioners communicate and manage to collaborate is essential to reach a shared understanding of the factors that cause and maintain pain and disability $[6,13,14]$. Oosterhof et al. [6], for instance, interviewed both patients and practitioners about their interactions and identified several factors that play an important role in reaching a shared understanding of a patient's pain. These include a clear explanation of the pain and the patient's experience of being taken seriously. Also, the practitioner's involvement with the patient and the experience of open communication were found to be important [6].

Although the importance of good communication is being increasingly recognised, there is a dearth of research on how the joint exploration of social and psychological factors by patients and their practitioners may be enhanced [15]. Several studies have taken a cognitivist psychological perspective. That is, the resistance that practitioners perceive is attributed to the patient's mental state, for example in terms of a lack of motivation or readiness to approach his/her pain from a biopsychosocial perspective. It has for example been argued that patients may be insufficiently motivated as a consequence of their erroneous expectations with regard to the rehabilitation programme [16-18]. Patients may for example hope and expect that the treatment will provide a biomedical solution to decrease their pain. Its basic principle, however, is to reduce pain-related disability by teaching patients to think about and deal with their pain and its associated problems differently. In a similar vein, King et al. [7] have suggested that patients may be unready to reconceptualise their pain because of their strong beliefs about their pain. Nonetheless, pretreatment communication aiming to manage patients' expectations and strengthen their motivation does not necessarily lead to better results $[17,19]$.

Another strand of research has approached the question from a different angle, by addressing the complex role of validation (i.e. the acknowledgement of a patient's feelings and experiences) in patient-practitioner interactions $[15,20]$. That is, health care professionals may be hesitant to provide validation because of a legitimate worry that it may increase pain behaviours, while at the same time, acknowledging patients' feelings and experiences increases the likelihood that they engage in disclosure $[15,20]$.

In short, there is growing recognition that good communication between patients and their practitioners is important to yield positive effects, but the current scientific literature does not sufficiently pinpoint the problem. The question of how a joint exploration of the social and psychological factors involved in the patient's pain can be enhanced, cannot yet be answered.

\subsection{Talking about chronic pain may be a delicate practice}

We suggest that answers may be found by taking a much closer look at what happens during the conversations between patients and their healthcare providers. After all, not only the literature on validation, but also the literature on stigmatisation shows that talking about chronic pain may be a rather delicate practice. This literature for example suggests that the lack of a clear biomedical explanation of the pain and the absence of visible signs of illness pose a threat to the patient's identity in interactions with others, including healthcare providers. Patients, for example, report having feared or experienced accusations 
of malingering, hypochondria, and mental illness [21-23], accusations that can all be associated with character blemishes [24]. Various studies suggest that these (potential) accusations affect how patients present themselves and their complaints to others [25-28]. Werner et al. [28] for example concluded that, in their interviews, women with chronic pain negotiated a picture of themselves that fitted with normative, biomedical expectations with respect to illness.

Phenomena as described above have not yet been studied in real-life conversations about chronic pain. Therefore, it remains unclear how potentially delicate issues, such as the legitimacy of chronic pain, are treated in real-life conversations between patients and practitioners. However, patients' resistance as reported by practitioners may signal the potential delicacy of social and psychological explanations.

\subsection{A discursive psychological perspective on conversations about chronic pain}

In order to understand why patients with chronic pain do not always seem open to talking about the psychological and social aspects of their pain, we might need to shed a different light on the way such aspects are discussed. In this paper, we suggest not treating the way patients talk about their health situation as merely a representation of some underlying mental state (e.g. in terms of willingness or readiness to accept psychosocial explanations). Instead, we need to be aware that the things people say are just as much socially produced [29]. When talking about their health situation to others, patients face particular dilemmas that influence the way they describe their situation [30-32]. Horton-Salway [32] illustrates how patients with chronic fatigue syndrome (CFS) may for example anticipate potential accusations of malingering and psychological vulnerability - for instance, by constructing CFS as a disease with a biomedical origin and by presenting themselves as people who always enjoyed being physically active (and thus not the type of person who wishes for a sedentary lifestyle). In other words, by emphasising certain aspects of their situation, patients may manage delicate matters.

In this article, we introduce discursive psychology [33] as a potentially valuable research perspective to gain a better understanding of delicate actions in conversations between patients with chronic pain and their practitioners. This perspective allows for such conversations to be studied on a micro level. The focus is not on identifying the cognitive states or processes that may underlie how people express themselves, but on how such psychological categories are build up and used by people as they interact [29]. Discursive psychology is, in other words, concerned with the social practices that people perform as part of a specific interactional context [29, 34]. How, for example, are attitudes and identities constructed in institutional interactions, such as medical consultations? And, most importantly, what interactional effects are achieved by these constructions?

In this article, we aim to show the merits of analysing patient-practitioner interactions on chronic pain from a discursive psychological research perspective. To do so, we first further explain the discursive psychological perspective, starting with an introduction to the three core principles of discursive psychology. Next, we illustrate how a discursive psychological research perspective may help to identify the specific sensitivities of a particular interactional context. As we shall show, discursive psychological analyses contribute to our understanding of the difficulties in conversations between patients with chronic pain and their practitioners. Moreover, such an understanding offers a gateway towards improving these conversations.

\section{The core principles of discursive psychology}

Discursive psychology (DP) is guided by three core principles that form the basis for its analytical rules and practices [29, 33]. In this section, we address them one by one. However, as will become clear, in DP these principles are strongly intertwined.

In the following sections, we explain the core principles of DP by using a small fragment of patient-practitioner interaction, see Extract 1 . The lines in bold reflect the original production of talk in Dutch. The English translation is provided in the lines below. We opted for a translation that is as literal as possible. However, in some cases, practical compromises had to be made, for example in order to convey the meaning of the original content or to secure the readability of the translation. A glossary of transcript symbols can be found in the Appendix.

Extract 1 is part of the patient's first consultation at the rehabilitation centre. The patient $(\mathrm{Pa})$, a rehabilitation physician (RP), and a rehabilitation physician trainee (not part of the fragment) are present. The transcript starts after a brief exchange between the rehabilitation physician and the rehabilitation physician trainee, about who is going to sit where. In this extract, we see how the rehabilitation physician invites the patient to sit down (line 1), after which the patient indicates having deliberately remained standing (line 4); this then leads to a sequence of questions and answers concerning the patient's reasons for remaining standing (lines 5-12). 


\section{Extract 1}

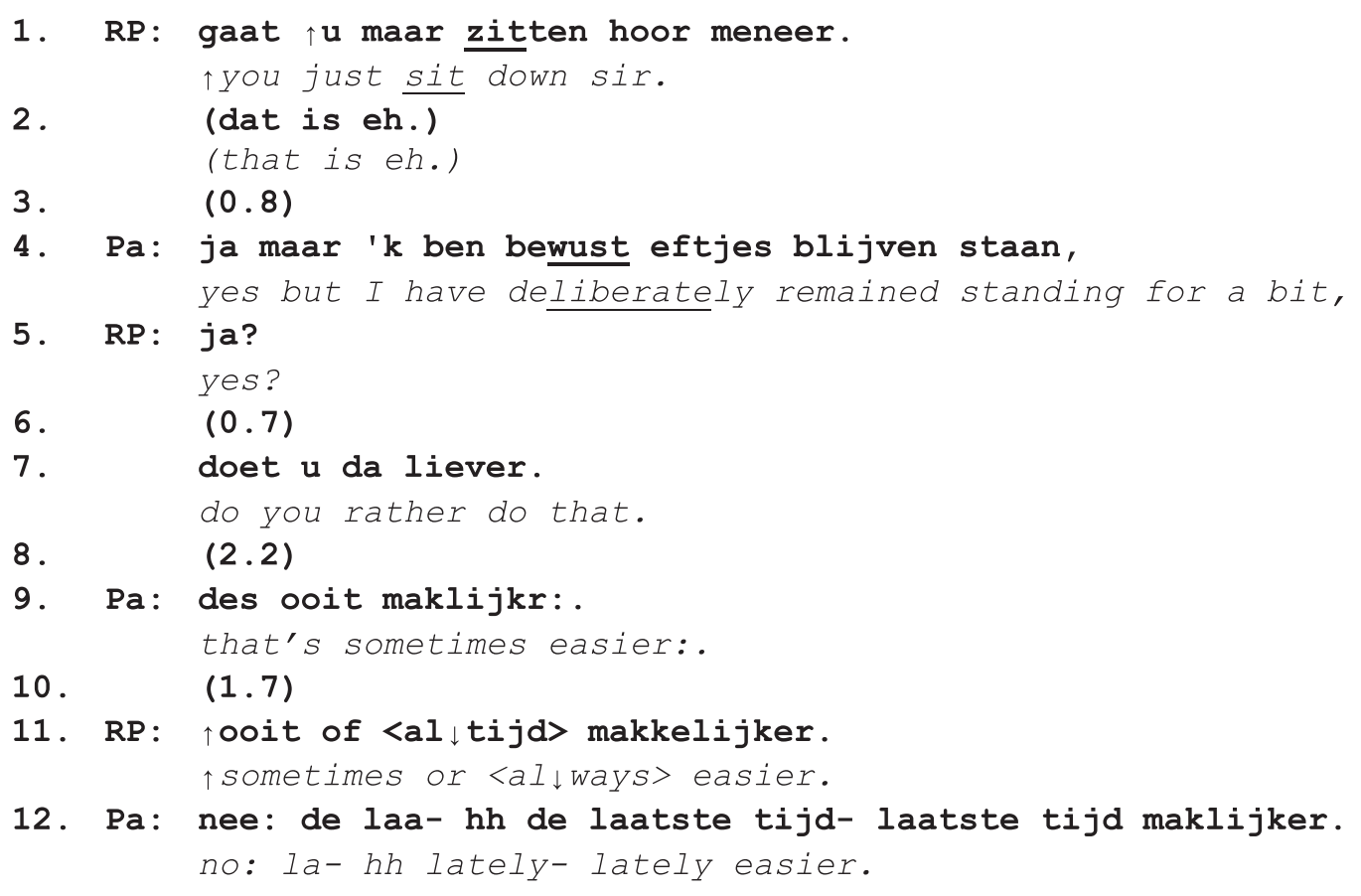

\subsection{Discourse is constructed and constructive}

The first core principle of DP is that people's talk is both constructed and constructive $[29,33]$. It is constructed from linguistic building blocks, such as words, metaphors, idioms, rhetorical devices, intonation, silences, and so on. From Extract 1, we can for example observe that this piece of discourse is constructed of, amongst other things, particular words, several silences (lines 3, 6, 8, and 10), and shifts in intonation (e.g. lines 1 and 11). People's talk is also constructive of different versions of the world, in the sense that through the way we talk - for example about ourselves and our health situation - particular versions of reality take shape. Whereas specifically sitting down (line 1) and standing (line 4) are referred to in Extract 1, a version of events is constructed in which both of these poses may be options during a consultation (although lying down, for example, may not be an option). Also, we can observe that a version of reality is constructed in which sitting down is the normative option. After all, the 0.8 silence (line 3) and the patient's "yes but I have deliberately remained standing for a bit" (in line 4) following the physician's invitation (lines 1 and 2) show that not sitting down is treated as something that needs to be accounted for.

\subsection{Discourse is situated}

It is important to note that the way people present particular realities always relates to the context in which they do so.
According to DP, it is therefore important to study people's productions of reality in the very specific, natural setting in which the interaction occurs [34]. This relates to the second core principle of DP, that people's talk is situated [29, 33].

First, it is situated within a specific interactional setting, such as chatting with friends at the pub, being interviewed by a researcher, or in this particular case: talking to a rehabilitation physician at the rehabilitation centre. It is particularly interesting, then, to see how the participants themselves orient to the context of the interaction [29, 33]. In Extract 1, for example, we see how the rehabilitation physician orients to his professional identity. He invites the patient to sit down and asks the patient specific questions, thereby acting as a host and taking the lead in this conversation, in which it is his job to collect information relating to the patient's health condition. Likewise, the patient orients to his role as a patient, who has the task of providing the rehabilitation physician with accurate and potentially relevant information about his health situation. Also, it becomes clear that, within this particular interactional context, the reasons for choosing a particular pose over another are oriented to as potentially relevant by both the patient and the rehabilitation physician.

Second, discourse is situated rhetorically [29, 33]. That is, because discourse will always be constructive of a particular version of events, it will at the same time either explicitly or indirectly - be countering alternative versions. To clarify this further, let us take a closer look at both the rehabilitation physician's question "Do you rather do that" (line 7) and the patient's answer "that's 
sometimes easier" (line 9). We can see that, in the physician's question, standing is constructed as a potentially favourable pose for the patient. Such a construction leaves open a range of possible underlying motivations. However, by describing standing as "sometimes easier", the favourability of sitting down is reworked into a more specific matter of ability, thereby countering a whole range of other possible versions (such as that standing is more favourable, as the patient is a very active person who finds standing pleasanter, or because standing is considered to be healthier, and so on).

Third, people's utterances are situated within the sequence of the particular interaction and thus should be interpreted in relation to the surrounding talk [29, 33]. As we have just seen while trying to make sense of the patient's "that's sometimes easier" (line 9), it was helpful to analyse it in relation to the rehabilitation physician's question preceding this utterance. In order to understand what an utterance is doing, it is also important to look at what comes after. This will become clear in the following section, which deals with the action orientation of discourse.

\subsection{Discourse is action oriented}

In the preceding two sections, we illustrated how discourse is both constructive and situated. Now, if we bring those together, it logically follows that people may consciously or unconsciously choose "versions" or ways of describing things that supposedly work out best for the particular occasion [29]. This idea that talk may "work out" in certain ways brings us to the third core principle of DP, that people's talk is action oriented [29, 33]. People do and accomplish things with talk. They perform all kinds of social actions, such as inviting someone to sit down (the physician in line 1) or refusing an invitation and accounting for their behaviour (the patient in line 4). In contrast to cognitivist psychology however, DP does not aim to draw any conclusions regarding whether and how discourse might relate to participants' thought processes, such as participants' intentions. Instead, it looks at what their talk actually does [29].

By choosing one version over another to describe something, either consciously or unconsciously, participants perform particular actions. One important way to identify these actions is by looking at how participants in a conversation themselves display their understanding of an utterance [34]. For example, note how the patient's contribution "yes but I have deliberately remained standing for a bit" in line four functions for more than just accounting for the refusal to sit down. If we look at what comes after, it becomes clear that it also subtly opens up the floor for the practitioner to ask potentially medically relevant questions about the patient's reasons to remain standing (see lines 7 and 11). Interestingly, we can identify this subtle action only by studying how the rehabilitation physician orients to the patient's contribution.

\section{DP reveals interactional sensitivities}

In the preceding section, we highlighted DP's interest in the action orientation of talk. DP focuses on how psychological categories - like attitudes, intentions, or perceptions - are "constructed, understood and displayed as people interact” (32 p93). For example, rather than approaching attitudes or evaluations (such as the patient's “that's sometimes easier" in Extract 1, line 9) as reflecting a person's inner world, they are treated as evaluations that are socially constructed and that are part of discourse practices [35]. The focus of DP, then, is on what people are doing with evaluations within particular contexts. What is being examined is: how are such psychological categories built up and how are they being used in interaction? In this section, we show how this type of examination of talk provides insight into the specific sensitivities in a particular interactional context. This time, we use a somewhat larger fragment of patientpractitioner interaction, which is presented in two pieces: Extract 2A and Extract 2B.

\subsection{Talk may make available potentially unfavourable inferences}

We use Extract 2 to show that talk can become delicate when it makes available certain potentially unfavourable inferences, for example about the speaker him/herself or about his/her conversation partner. For instance, as there is a moral imperative for people to maintain their health wherever possible, patients run the risk of being treated as morally culpable when their health problems are constructed in terms of consequences of their own actions [36]. According to DP, participants in interaction tend to manage the potential interactional consequences of such unfavourable inferences.

Let us look at an example. Extract 2A and Extract 2B are part of a patient's visit to the psychologist at a rehabilitation centre, taking place after the rehabilitation team's examination of the patient's situation. Within this particular consultation, the psychologist (Ps) informs the patient $(\mathrm{Pa})$ about the rehabilitation team's observations and discusses treatment possibilities. 


\section{Extract 2A}

1. Ps: . hh we $\uparrow \mathbf{z a g e n}$ wel wat andere aanknopingspunten waarvan:= .hh we did $\uparrow$ see some other clues of which:=

2. Ps: =dachten van $\downarrow$ nou.=.hhh dat is misschien sowieso wel (.) =thought like $\downarrow$ well.=.hhh that is maybe anyhow (.)

3. Ps: ver $\downarrow$ klarend voor (.) de (.) pijnklachten die=

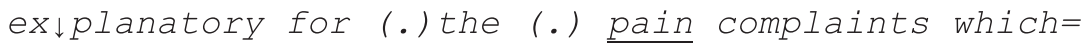

4. Ps: =je een parr maanden hebt. =you've had a couple of months.

5. Ps: die ver $\downarrow$ springende pijnklachten [hè? those $\downarrow$ moving pain complaints [right?

6. $\mathrm{Pa}$ :

7. Ps: das ook een eh stukje wat wat ((naam revalidatiearts))= that's also a eh part of which which ((name rehabil. physician))=

8. Ps: al had aange[geven ] van nou. $=. \mathrm{hh} \uparrow^{\circ} \mathrm{hm}^{\circ}$ already had indi[cated] like well. $=. h h^{\circ}{ }^{\circ} \mathrm{hm}^{\circ}$

9. Pa: $\left[\left({ }^{\circ} \mathrm{ja}^{\circ}\right)\right]$

10. Pa: ja 't ['t]-

$$
\left[\left({ }^{\circ} y e s^{\circ}\right)\right]
$$

11. Ps: [d]oorzette:r en eh [hh] heheh heh=

12. $\mathrm{Pa}$ : [p] ersevere:r and eh [hh] heheh heh= [ja ]

13. $\mathrm{Pa}:=\mathrm{ja}=$ [yes]

$$
\text { =yes= }
$$

14. Ps: $=. h$ heh en daardoo[r eh] ja. is 't (i) is 't voor je-= $=. h h$ heh and therefo[re eh] yes. it's (i) it's for your-=

15. $\mathrm{Pa}$ : [heh ] [heh ]

16. Ps: =ja is 't voor je lijf moeilijker bij te benen [ $\uparrow$ eig]lijk. =yes it's harder for your body to keep up with [ $\uparrow$ act] ually.

17. $\mathrm{Pa}$ :

\section{[ja $]$} [yes]

18. Ps: . hh ehm (0.5) dus ehm dat is $\uparrow$ wel iets waarvan we (z) $\downarrow \mathbf{z}:$ eiden= .hh ehm (0.5) so ehm that $\uparrow$ is something of which we (s) $\downarrow$ s:aid=

19. Ps: =van ja weet je dat $\uparrow$ heeft wel aandacht nodig, like yes you know that $\uparrow$ does need attention,

20. Ps: dat was iets wat je nie zo duidelijk (.) verder (.) that was something which you had not that clearly (.) further (.)

21. Ps: aan (.) ja .hh >aan aan aan< de fysiotherapeut had geme:ld, reported (.) well.hh >to to to< the physiotherapist,

22. Ps: .hh dat die lichaa[mlijke klachte=eh .hh that those physi[cal complaints=eh

23. $\mathrm{Pa}$ :

$$
\begin{aligned}
& {\left[^{\circ}(j a)^{\circ}\right.} \\
& {\left[^{\circ}(\text { yes })^{\circ}\right.}
\end{aligned}
$$


In Extract 2A, we see that the psychologist carefully introduces a potential explanation for the patient's pain complaints. In doing so, she refers to the patient as the type of person who perseveres (line 11). The Dutch expression doorzetter is idiomatic and does not translate into English. It is derived from the verb doorzetten, which means "to persevere". Although not common in English, its literal translation would be "perseverer". In Dutch, doorzetter generally has a positive connotation, as it is often used to characterise people who do not "just give up". However, in this case, the character trait is being introduced as explanatory of the patient's pain complaints (lines 1-5), which the psychologist further explains as a matter that has consequences for the body, which has a hard time keeping up (lines 14-16).

The explanation of the patient's complaints as introduced by the psychologist is delicate, as it implicitly carries the accusation that the patient can be held personally accountable for her own complaints. After all, the explanation suggests that the patient's complaints are a consequence of her own persevering behaviour.

If we take a closer look, we can see that both the psychologist and the patient orient to this tension. The psychologist does not "just" introduce the patient's persevering character as an explanation, she does so in a rather cautious way, which involves interactional effort.
First of all, she does not introduce this account as her personal opinion, but as based on clues, which the team ("we", line 1) did see (line 1). She thus presents the explanation as one that is shared and observable, thereby establishing the factuality of the claim [37]. So-called active voicings [38] of the team's thoughts and statements (lines 1-4: "thought like well. hhh that is maybe anyhow explanatory for the pain complaints which you've had a couple of months" and lines 18-19: "that is something of which we said like yes you know that does need attention") further work up the authenticity of the team's consensus and suggest that the account has come about in a considered way.

Secondly, at lines 7, 8, and 11, she presents the behavioural explanation, as if she is citing the rehabilitation physician, thereby distancing herself from this particular formulation [39]. Presenting a description as a report by someone else, also called distanced footing, decreases the speaker's accountability for the utterance [37]. And finally, the laughter in lines 11 and 14 also displays the psychologist's orientation to the sensitivity of the explanation. Several studies have shown that, in medical interaction, laughter may be used to alleviate delicate activities [40-42], such as the delivery of a confrontation by the practitioner [42].

In Extract 2B, we can see that the explanation is in fact also taken up as a sensitive issue by the patient.

\section{Extract 2B}

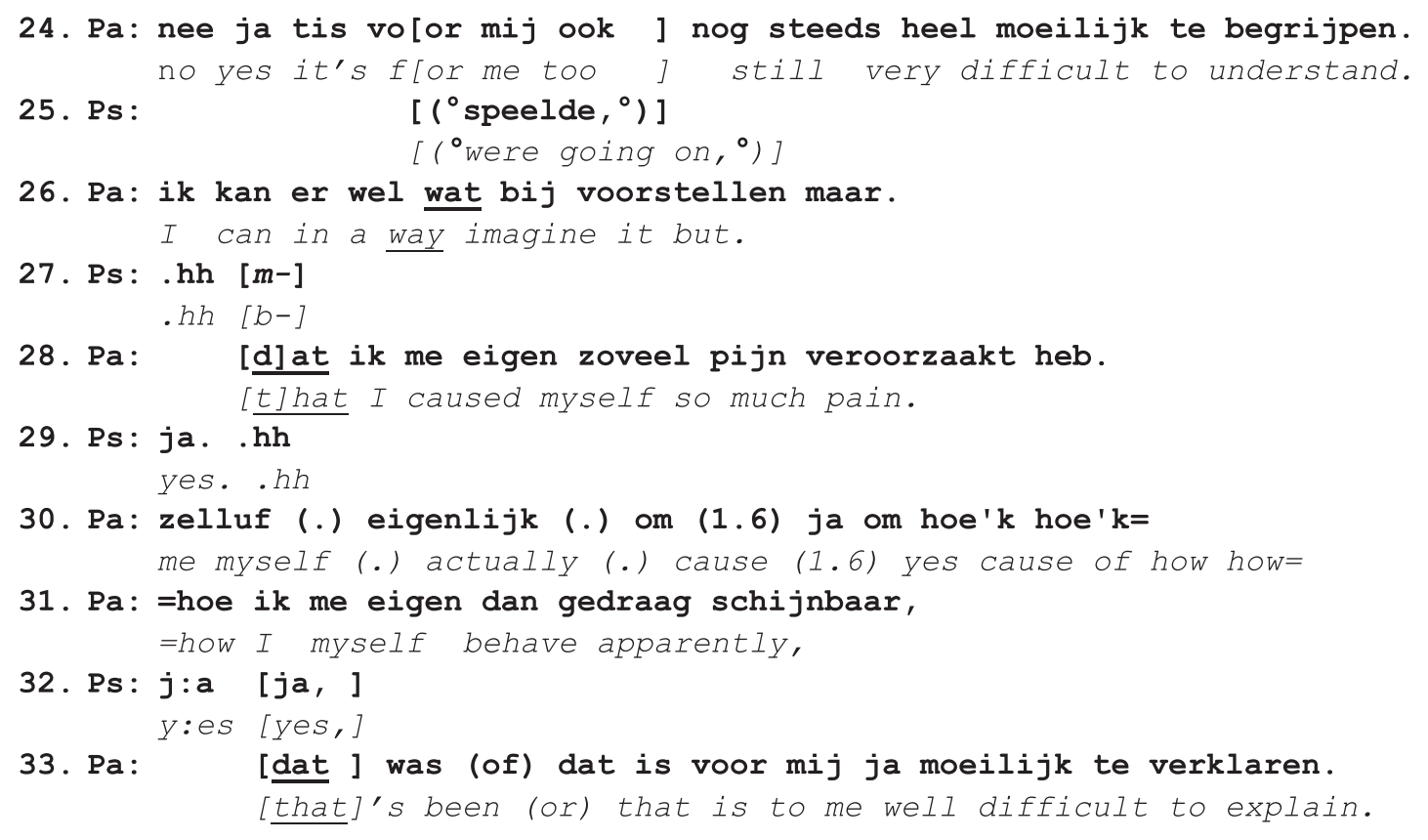


The patient indicates that for her too it is "still very difficult to understand" (lines 24) and that she can "in a way imagine" (line 26) having caused herself so much pain. She therewith counters any inference that she would have knowingly persisted in harmful behaviour. After a considerable pause (1.6 s), by which the patient displays hesitance, she adds "yes cause of how how how I myself behave apparently" (lines 30-31); this further contributes to undermining any inference that her behaviour would be deliberate. That is, the word "apparently" suggests that her behaviour is something of which she is not in any way aware. It works to underline that the causal link with her pain complaints was and, as line 33 suggests, still is beyond the powers of her imagination. The patient thus subtly manages to partially align with the psychologist's account that her persevering character is an explanation for her pain complaints, while simultaneously presenting her behaviour as not blameworthy. ${ }^{1}$

\subsection{Using DP to identify interactional concerns and discursive strategies}

In the previous section, we provided an illustration of how participants in a conversation anticipate the potentially unfavourable inferences of their talk. Analysing the turns in interaction clarified the elements in the interaction to which the participants oriented as sensitive. In other words, DP can be used to gain insight into how people themselves display certain sensitivities in a particular interactional context. In this section, we further explain some central notions of DP that are related to these kinds of sensitivities and the way in which they can be identified.

In our example analysis, the sensitivities to which the participants oriented in interaction had to do with a potentially critical stance by their conversation partner. In DP terms, such a potentially critical stance is generally referred to as a potential accusation of stake. That is, participants run the risk that what they say or do may be discounted as a product of stake or interest [37, 43, 44].

The sensitivities relating to potential accusations of stake, such as observed in our example analysis, can be described as participants' interactional concerns [37, 45]. It is important to note that all of the participants in

\footnotetext{
1 Note that by presenting the issue as something that is beyond her comprehension, she also manages to counter a second potential accusation that is available in the psychologist's talk, that is, that she would have failed to report information regarding her complaints to the physiotherapist (see lines 20-22 and 25). After all, she was not aware of what was happening.
}

a conversation deal with those. In the previous piece of patient-practitioner interaction, it was not only the patient who dealt with an interactional concern: to balance between showing herself as receptive to a behavioural explanation of her pain and managing responsibility for her pain. The psychologist too had to deal with a concern: how to deliver a behavioural explanation of the patient's pain, without discrediting the patient.

Participants' interactional concerns are usually only implicitly available in interactions [37]. They can be revealed by studying the actions that participants perform as they interact, that is, by identifying participants' discursive strategies to anticipate or solve their interactional concerns [37, 45]. In Extract 2B, we saw, for example, how the patient depicted her persevering behaviour as undeliberate, thereby heading off the potential accusation that she was culpable for her pain. Also, we saw how the psychologist presented the explanation as factual and arrived at in a considered way, rather than judgemental.

An important way for discursive psychologists to identify discursive strategies is by utilising discursive devices that contribute to these kinds of discursive strategies. These are recognisable features of discourse that help participants to perform social actions and that are recurrent in diverse interactional contexts [29]. In our analysis of the psychologist's way of talking in Extract 2A, we observed, for example, active voicing and distanced footing.

\section{DP as a promising approach to enhance patient-practitioner interaction}

In this paper, we have argued that DP provides a fruitful research approach to gain significant insights into the specific sensitivities of patient-practitioner interaction in chronic pain rehabilitation. We believe that such insights could contribute to a better understanding of particular interactional difficulties that have been reported, particularly with respect to patients' resistance to practitioners' social and psychological explanations of their pain [11]. Analysing interactions between patients with chronic pain and their practitioners from a DP research perspective may shed a different light on what is perceived as patients' resistance. That is, maybe the ways in which patients tend to respond to certain social and psychological explanations of their pain should not in the first place be treated as reflecting resistance to these explanations per se. Instead, 
they might need to be seen as ways to solve particular interactional concerns that may be consequential to the potential inferences of these psychosocial explanations. Findings by Burbaum et al. [46] support such a hypothesis for a different interactional context. These authors studied the interactional concerns and discursive strategies of patients with medically unexplained symptoms and their psychotherapists in consultations during a short-term psychotherapeutic hospital intervention. Their analysis of patients' discursive strategies in response to their therapists' psychosomatic explanations showed that patients treated these explanations as identity threatening.

It is important to emphasise that patients' interactional concerns do not simply follow from the delicate nature of social and psychological explanations as such, but rather are bound up with how such explanations are delivered by the practitioner. DP studies will therefore also provide important insights with respect to the communicative strategies of practitioners. DP studies of patient-practitioner interactions therefore not only provide practitioners with a better understanding of what is going on in their conversations with patients, but also can be used to develop communication skills training that helps practitioners to reflect on their own communication practices [44, 47]. The identification of recurrent interactional concerns and discursive strategies in patient-practitioner interaction that hinder patients with chronic pain and their practitioners from arriving at a shared understanding of the pain will equip practitioners with directions for improving their communication practices. What ways of formulating particular psychosocial explanations, for example, tend to enhance an open conversation about the social and psychological factors that might be involved in the patient's pain and pain-related disabilities? Insights from DP research could therefore contribute to patient-practitioner interactions that are more enabling and stimulating for patients to explore these social and psychological factors, and to arrive at a biopsychosocial understanding of their pain that is shared by them and their practitioners.

\section{Authors' statements}

Research funding: Authors state no funding involved.

Conflict of interest: Authors state no conflict of interest. Informed consent: Informed consent was obtained from all individuals in this study.

Ethical approval: The research has been approved by an accredited Research Ethics Committee: METC Z, The Netherlands (reference number: 17-N-160).

\section{Appendix}

Appendix: Transcription symbols, based on Jefferson [48] transcription system.

\begin{tabular}{|c|c|}
\hline [] & Square brackets indicate overlapping speech \\
\hline$=$ & Equal signs indicate no break/gap \\
\hline 00 & Degree signs indicate speech that is quieter than the surrounding talk \\
\hline$><$ & indicates that the bracketed talk is delivered faster than the surrounding talk \\
\hline$<>$ & indicates that the bracketed talk is slowed down, compared to the surrounding talk \\
\hline (.) & A dot in round brackets indicates a micro-pause, hearable but too short to measure \\
\hline$(1.6)$ & Numbers in round brackets measure pauses in (tenths of) seconds \\
\hline word & Underlining indicates emphasis \\
\hline : & Colons signal a prolongation of the preceding sound \\
\hline$\uparrow \downarrow$ & Arrows indicate a rise or fall in intonation \\
\hline • & A full stop indicates a falling intonation \\
\hline , & A comma marks a slightly rising intonation \\
\hline ? & A question mark signals a rising, questioning intonation \\
\hline$(($ writing $))$ & Double brackets refer to transcriber's descriptions of features or non-verbal aspects of the interaction \\
\hline. $\mathrm{hh}$ & A dot preceding (a row of) " $h$ " indicates an in-breath \\
\hline $\mathrm{hh}$ & (A row of) " $h$ " indicates an outbreath \\
\hline heheh & Indicates laughter \\
\hline w(h)ord & Laughter within speech is signalled by “ $h$ ” in round brackets \\
\hline$(m)$ & A parenthesised italicised letter indicates an incipient sound \\
\hline- & A dash indicates a cut-off \\
\hline () or (word) & Empty space between brackets or words between brackets respectively indicate inaudible speech and uncertain $\mathrm{h}$ \\
\hline
\end{tabular}




\section{References}

[1] Nicholas MK, Linton SJ, Watson PJ, Main CJ. Early identification and management of psychological risk factors ("yellow flags") in patients with low back pain: a reappraisal. Phys Ther 2011;91:737-53.

[2] Hasenbring MI, Rusu AC, Turk DC. From acute to chronic back pain. New York: Oxford University Press, 2012.

[3] Gatchel RJ, Peng YB, Peters ML, Fuchs PN, Turk DC. The biopsychosocial approach to chronic pain: scientific advances and future directions. Psychol Bull 2007;133:581-624.

[4] Scascighini L, Toma V, Dober-Spielmann S, Sprott H. Multidisciplinary treatment for chronic pain: a systematic review of intervention and outcomes. Rheumatology 2008;47:670-8.

[5] Gatchel RJ, Okifuji A. Evidence-based scientific data documenting the treatment and cost-effectiveness of comprehensive pain programs for chronic nonmalignant pain. J Pain 2006;7:779-93.

[6] Oosterhof B, Dekker JHM, Sloots M, Bartels EAC, Dekker J. Success or failure of chronic pain rehabilitation: the importance of good interaction - a qualitative study under patients and professionals. Disabil Rehabil 2014;36:1903-10.

[7] King R, Robinson V, Ryan CG, Martin DJ. An exploration of the extent and nature of reconceptualisation of pain following pain neurophysiology education: a qualitative study of experiences of people with chronic musculoskeletal pain. Patient Educ Couns 2016;99:1389-93.

[8] Moseley G. Reconceptualising pain according to modern pain science. Phys Ther Rev 2007;12:169-78.

[9] Verbeek J, Sengers M, Riemens L, Haafkens J. Patient expectations of treatment for back pain: a systematic review of qualitative and quantitative studies. Spine (Phila Pa 1976) 2004;29:2309-18.

[10] Frantsve L, Kerns R. Patient-provider interactions in the management of chronic pain: current findings within the context of shared medical decision making. Pain Med 2007;8:25-35.

[11] May CR, Rose MJ, Johnstone FCW. Dealing with doubt: how patients account for non-specific chronic low back pain. J Psychosom Res 2000;49:223-5.

[12] Swaan J, Schiphorst Preuper H, Smeets R. Multifactorial analysis in specialized medical rehabilitation [Multifactoriële analyse in de medisch-specialistische revalidatie]. In: Verbunt J, Swaan J, Schiphorst Preuper H, Scheurs K, editors. Handbook of pain rehabilitation: for primary, second-line and third-line medical care [Handboek pijnrevalidatie: Voor de eerste-, tweede-en derdelijnsgezondheidszorg]. Houten: Bohn Stafleu Van Loghum, 2019:69-85.

[13] Coran J, Koropeckyj-Cox T, Arnold C. Are physicians and patients in agreement? Exploring dyadic concordance. Heal Educ Behav 2013;40:603-11.

[14] de Jong J, Vlaeyen J, Onghena P, Goossens M, Geilen M, Mulder H. Fear of movement/(re) injury in chronic low back pain: education or exposure in vivo as mediator to fear reduction? Clin J Pain 2005;21:9-17.

[15] Linton SJ. Intricacies of good communication in the context of pain: does validation reinforce disclosure? Pain 2015;156:199-200.

[16] Goossens M, Vlaeyen J, Hidding A, Kole-Snijders A, Evers S. Treatment expectancy affects the outcome of cognitive-behavioral interventions in chronic pain. Clin J Pain 2005;21:18-26.
[17] Mertens V. 'Be prepared!: motivational interviewing as pre-treatment in chronic pain rehabilitation [dissertation]. Maastricht: Maastricht University, 2015.

[18] Smeets R, Beelen S, Goossens M, Schouten E, Knottnerus J, Vlaeyen J. Treatment expectancy and credibility are associated with the outcome of both physical and cognitive-behavioral treatment in chronic low back pain. Clin J Pain 2008;24:305-15.

[19] Mertens V, Goossens M, Verbunt J, Köke A, Smeets R. Effects of nurse-led motivational interviewing of patients with chronic musculoskeletal pain in preparation of rehabilitation treatment (PREPARE) on societal participation, attendance level, and costeffectiveness: study protocol for a randomized control. Trials 2013;14:1-14.

[20] Edmond SN, Keefe FJ. Validating pain communication: current state of science. Pain 2015;156:215-9.

[21] Holloway I, Sofaer-Bennett B, Walker J. The stigmatisation of people with chronic back pain. Disabil Rehabil 2007;29:1454-64.

[22] Åsbring P, Närvänen A. Women's experiences of stigma in relation to chronic fatique syndrome and fibromyalgia. Qual Health Res 2002;12:148-60.

[23] Nettleton S. 'I just want permission to be ill': towards a sociology of medically unexplained symptoms. Soc Sci Med 2006;62:1167-78.

[24] Glenton C. Chronic back pain sufferers - striving for the sick role. Soc Sci Med 2003;57:2243-52.

[25] Ong BN, Hooper H, Dunn K, Croft P. Establishing self and meaning in low back pain narratives. Sociol Rev 2004;52:532-49.

[26] Smith JA, Osborn M. Pain as an assault on the self: an interpretative phenomenological analysis of the psychological impact of chronic benign low back pain. Psychol Heal 2007;22:517-34.

[27] Osborn M, Smith JA. The personal experience of chronic benign lower back pain: an interpretative phenomenological analysis. Br J Health Psychol 1998;3:65-83.

[28] Werner A, Isaksen L, Malterud K. 'I am not the kind of woman who complains of everything': illness stories on self and shame in women with chronic pain. Soc Sci Med 2004;59:1035-45.

[29] Wiggins S. Discursive psychology. Theory, method and applications. London: Sage, 2017.

[30] Horton-Salway M. Mind and body in the discursive construction of ME: a struggle for authorship of an illness [dissertation]. Loughborough: Loughborough University, 1998.

[31] Horton-Salway M. The construction of ME: the discursive action model. In: Wetherell M, Taylor S, Yates S, editors. Discourse as data: a guide for analysis. London: Sage, 2001.

[32] Horton-Salway M. Narrative identities and the management of personal accountability in talk about ME: a discursive psychology approach to illness narrative. J Health Psychol 2001;6:247-59.

[33] Wiggins S, Potter J. Disursive psychology. In: Willig C, StaintonRogers W, editors. The SAGE handbook of qualitative research in psychology, 2nd ed. London: Sage Publications Ltd., 2017:93-109.

[34] Potter J, Hepburn A. Discursive psychology as a qualitative approach for analysing interaction in medical settings. Med Educ 2005;39:338-44.

[35] Potter J. Discursive social psychology: from attitudes to evaluative practices. Eur Rev Soc Psychol 1998;9:233-66.

[36] McKinlay A, McVittie C. Identities in context. Individuals and discourse in action. Chichester: Wiley-Blackwell, 2011. 
[37] Potter J. Representing reality: discourse, rhetoric and social construction. London: Sage, 1996.

[38] Wooffitt R. Telling tales of the unexpected: a sociological analysis of accounts of paranormal experiences [dissertation]. York: University of York, 1989.

[39] Goffman E. Footing. Semiotica 1979;25:1-29.

[40] Haakana M. Laughter as a patient's resource: dealing with delicate aspects of medical interaction. Text 2001;187-219.

[41] Zayts 0, Schnurr S. Laughter as medical providers' resource: negotiating informed choice in prenatal genetic counseling. Res Lang Soc Interact 2011;44:1-20.

[42] Arminen I, Halonen M. Laughing with and at patients: the roles of laughter in confrontations in addiction group therapy. Qual Rep 2007;12:484-513.

[43] Edwards D, Potter J. Discursive psychology. London: Sage, 1992.

[44] Lamerichs J, Te Molder H. Reflecting on your own talk: the discursive action method at work. In: Antaki C, editor. Applied conversation analysis: intervention and change in institutional talk. London: Palgrave Macmillan UK, 2011:186-206.

[45] Lamerichs J, Koelen M, Te Molder H. Turning adolescents into analysts of their own discourse: raising reflexive awareness of everyday talk to develop peer-based health activities. Qual Health Res 2009;19:1162-75.

[46] Burbaum C, Stresing A-M, Fritzsche K, Auer P, Wirsching M, Lucius-Hoene G. Medically unexplained symptoms as a threat to patients' identity? A conversation analysis of patients' reactions to psychosomatic attributions. Patient Educ Couns 2010;79:207-17.

[47] Stokoe E. Simulated interaction and communication skills training: the 'Conversation-Analytic Role-Play Method'. In: Antaki C, editor. Applied conversation analysis: intervention and change in institutional talk. London: Palgrave Macmillan UK, 2011:119-39.

[48] Jefferson G. Glossary of transcript symbols with an introduction. In: Lerner G, editor. Conversation analysis: studies from the first generation. Amsterdam: John Benjamins Publishing Company, 2004:13-32.

Article Note: The data presented in Extracts 1, 2A, and 2B were collected as part of the authors' current study into patient-practitioner interaction in interdisciplinary chronic pain rehabilitation in the Netherlands. 